\title{
Using Team Teaching to Teach English for Academic Purposes in Large Classes: A Case for Nigerian Tertiary Institutions
}

\author{
Emmanuel C Sharndama ${ }^{1} \&$ Yusuf Ishaya Tsokjon ${ }^{1}$ \\ ${ }^{1}$ Faculty of Humanities, Management and Social Sciences, Federal University, Wukari \\ Correspondence: Emmanuel C Sharndama (PhD), Department of English and Literary Studies, Faculty of \\ Humanities, Management and Social Sciences, Federal University, Wukari. Tel: 802-677-6862/816-010-9030. E-mail: \\ esharndama@gmail.com
}

Received: November 23, 2013 Accepted: December 18, 2013 Online Published: December 21, 2013

doi:10.5430/ijelt.v1n1p94 URL: http://dx.doi.org/10.5430/ijelt.v1n1p94

\begin{abstract}
English Language Teaching (ELT) in English medium tertiary institutions of the world today takes different dimensions and focuses. There are also numerous challenges of teaching and learning English Language in the English medium tertiary institutions. One of the challenges is large class sizes especially in the developing countries. This paper has examined the use of team teaching as a means of enhancing teaching and learning of English for academic purposes in large classes. The study has revealed that there are different models of team teaching that could be utilized to enhance teaching and learning of EAP in large classes. Team teaching is a teaching strategy that harnesses different teachers' knowledge and teaching skills to enhance learning. The paper has suggested how to utilize team teaching models to enhance the teaching of EAP in large classes. It pointed out how differentiated split class model can be used to teach EAP in large class by splitting a class according to programme of studies which determine the needs of the learners instead of teaching General English.
\end{abstract}

Keywords: EAP/ESP, needs analysis, large classes, team teaching, team teaching models

\section{Introduction}

English for academic purposes tend to sound strange to the ears of many students in Nigerian tertiary institutions. It is often hidden under the wider term communication skills which encompass not only English but also study skills like the use of library and how to take lecture note. The term, "the use of English" is the most popular in Nigerian tertiary institutions of Learning. It is taught to students from different course backgrounds with the aim of enabling them to acquire proficiency in English and to improve their communicative competence. It is taught to beginning students of various tertiary institutions of Nigeria. The course contents comprise of basic grammar and writing tasks aimed at improving the students' proficiency and competence in English. One of the challenges of teaching English for academic purposes in Nigerian tertiary institutions today is large class sizes. Large classes are usually as a result of rapid increase in students' enrolment with shortage of teachers and space to match the teeming population. Lecturers normally end up adapting lecture method as they teach Sea of heads that they may know only few. Students from different course backgrounds converge in a big hall to receive the same lecture which is not based on specified students' needs. English for academic purposes as a branch of English for Specific Purposes is supposed to be taught based on the needs of students of each programme of study. This follows the popular slogan of ESP "tell me your problem and I will tell you the English language you need" (Hutchinson and Waters 1987).

Large classes are common in educational institutions of many countries of the world today. The reason is mostly attributed to the rapid increase in school enrolment every year. In some countries, little is done to provide human resources and facilities that will match the ever growing population of learners. Sometimes, a classroom designed to accommodate $40-50$ students will be used by 50-100 students; while a lecture theatre in tertiary institutions designed to accommodate 200-250 students may be used by 250-400 students

Most people believe that teaching a small group of students is easier, more enjoyable, and less time consuming than teaching a large class. Unfortunately, due to budgets, space, or lack of teachers, many ESL schools only offer large classes. In some schools, large classes may consist of up to 50 or more students. Although the class size may be large, the solution should not be adapting lecture method. The teacher should decide how to engage students in activities that will keep them interested and participating with the goal of improving their communication skills. While there 
are numerous challenges when it comes to teaching large classes, there are many coping skills and activities that you can use to make your job easier. (Tara 2008) This study adapts qualitative approach to describe how team teaching can be utilized as coping strategy for teaching English Language in large classes

\section{English for Specific Purposes}

English for Specific Purposes (ESP) is an approach to the teaching of English language guided by context in which the learner requires English. Unlike the teaching of General English which is not focused towards particular function and concentrates much on the teaching of grammatical structures, ESP is taught with focus on the English Language needed in a particular context. It is a learner-centred approach to teaching English which is geared towards developing communicative competence in a specific context/ discipline such as occupations, and academics. English for Specific purposes is designed to improve the learners' proficiency in English and expose them to real world communicative skills. It differs from General English because it is designed to meet the specific needs of the learners. The content of ESP course relates to themes and topics of particular a discipline or occupation. It also relies on authentic materials developed to meet the learners' needs. ESP in practice entails teaching English to group of learners with specific goals. It is against this background that English for Specific Purposes is considered as a learner-cantered approach to teaching of English as a foreign or second language.

Hutchinson and Waters (1987) refer to English for Specific Purposes as an approach to English Language teaching which has shifted focus away from the traditional structural treatments of language to discovering the ways in which language is used in real communication context. The development of ESP was one of the after maths of the Second World War. The end of the Second World War ushered in an age of enormous and unprecedented expansion in scientific, technical and economic activities on international scale. There became a need for a language to meet those demands of which the role fell on English.

Secondly, the crisis of the early 1970s resulted to western money and knowledge flowing into the oil-rich countries. The second factor according to Hutchinson and Waters (1987) was a revolution in linguistics. Traditionally, the aim of linguistics was to describe the rules of English usage, that is, the grammar. The new study however brought revolution by shifting attention away from defining or describing the formal features of language usage from discovering the ways in which language is actually used in real context of communication. The third factor as pointed out by Hutchinson and Waters (1987) was the focus on the learner. It was as the result of a new development in educational Psychology which contributed to the rise of ESP. The new development emphasized the central importance of the learners and their attitudes to learning. Learners were seen to have different needs and interest, which could have an important influence on their motivation to learn and therefore on the effectiveness of their learning.

The combination of these factors at the end of the Second World War as enumerated by Hutchinson and Waters (1987) led to the emergence of ESP-the demand of the brave new world, the revolution in linguistics and the focus on the learners' needs.

According to Ahsan (2009), the most important difference between General English and English for Specific Purposes lies in the learners and their purposes for learning English. Ahsan further opines that one can add to it by saying that ESP concentrates more on language in context than on teaching grammar and language structures. It covers subjects varying from accounting or computer science to tourism and business management. In some cases, people with inadequate proficiency in English need to be taught to handle specific jobs. In such cases English is taught for specific purposes so that the concerned employees can perform their job requirements efficiently

English for Specific Purposes (ESP) is a needs based concept to determine which language skills should be profitably developed for academic and professional success of students or employees. It takes into account certain basic questions like: "who are the learners? What is their linguistic background or level of competence? What is their view to language learning? What is their purpose and expectations?, What particular skill they will need in their actual, onthe- job situation? (Singh 2005) These questions are usually covered in needs assessment which marks the beginning of the teaching of English for specific purposes.

\section{English for Academic Purposes}

English for Academic Purposes is a branch of ESP taught in higher institutions to improve the learners' proficiency in English Language and to help them to overcome some of their difficulties in English as a medium of study. The teaching of EAP especially in English medium tertiary institutions is based on the assumption that the learners have already been taught English for General Purposes (EGP) at the primary and secondary school levels. At the higher levels, the learners need advance English Language Skills to enable them to pursue their academic course of studies 
and perform better at their working places after studies. According to Ahsan (2009), in many contexts, it has been felt that students require adequate English language skills in order for them to cope with the academic demands of their study programme. Hence a course of English for Academic Purposes (EAP) is designed and taught to them. Such a course includes the teaching of such skills as critical thinking, critical reading, listening for global and specific comprehension (e.g. lectures, talks, announcements, etc), writing essays, terms papers, critical analysis, reports, participation in group discussions, making oral presentations, etc.EAP programme helps to develop students' academic communication skills. It enhances successful completion of our Academic Writing especially at the end of a course.

The first stage in the teaching of EAP is to assess why the students are learning English and the skills they need. This is what is called needs analysis in the study of ESP. Mohammadi, and Mousavi (2013) opines that needs analysis is a means by which one can come up with what the learners already know, what they need to know, and, finally, what they want to know. In doing this, the learners' linguistic background -their weaknesses and strengths should be determined. Needs analysis result will enable the teacher to design a syllabus (course), develop material and decide on the appropriate method. This is why EAP is not taught based on any preordained methodology. The teaching of EAP is always integrated to real communicative contexts. Activities that the learners will engage in normally reflect the environment of language usage and the content. For the EAP teacher to be successful, the knowledge of the course content should be married to the language to be taught. The course content and the language content in the study of EAP are inseparable. Collaboration between the subject specialist and the EAP teacher sometimes becomes necessary.

In Nigeria, lack of space and teachers are what commonly compel school proprietors to run large classes. This means that splitting a large class requires more teachers and space. In tertiary institutions, students can be taught English for Academic purposes based on their programme of studies. Instead of overcrowding in one lecture hall, their programme lecture classes can be used. Once a large class is split, based on programme of studies, each language teacher will plan to teach based on the students' language needs. This implies that planning and teaching will be based on systematic needs analysis of the students than the generalized needs as obtains in English for General Purposes class.

\section{Needs Analysis}

The teaching of English for Specific Purposes usually begins with needs analysis. It involves actions taken to find out the learners' language background-what they already know and what they need to know and what they want to know. Needs analysis or assessment deals with collection of data/information on the learners in order to understand their language needs (strength and weaknesses). Iwali et al (1999),cited in Songhori(2008) describes needs analysis(NA) as generally refers to the activities that are involved in collecting information that will serve as the basis for developing a curriculum that will meet the needs of a particular group of students. The role of needs analysis in ESP is indisputable and cannot be overemphasized. Johns (1991) in Songhori (2008) for instance sees needs analysis as the first step in course designing and it provides validity and relevancy for all subsequent course design activities. This implies that needs analysis is determines the course content and the materials to be developed.

Brown (1995) cited in Mohammadi, \& Mousavi (2013) defines NA as "the systematic collection and analysis of all subjective and objective information necessary to define and validate defensible curriculum purposes that satisfy the language learning requirements of students within the context of particular institutions that influence the learning and teaching situation; while Dudley-Evans and St. John, (1998) describes NA as a means of establishing the "what and how of a course". This means that needs assessment as an activity is geared towards understanding the language back ground of the students as well as what to do in order to build up their background knowledge.

\section{What is Large Class?}

A large class is often notionally defined as there is hardly a conventional or a substantive definition. This is because the number of students that constitute a large class varies from one country to another. Some institutions or countries use the term "large class" to refer to classes of more than 50 students, while others regard a large class as one with more than 100 students ((UNESCO, 2006 cited in Bradley and Eric 2011). This means that a class that is considered as large in one country may be considered as small or normal in another. In Nigeria for example, a class of 50 in tertiary institutions is considered small or normal due to the fact that most of the classes even in engineering and sciences have more than 50 students. A large class irrespective of the number is one in which the teacher feels that his performance and what he is supposed to do is hampered by the population of the students. A large class has more students than the recommended class size; more students than learning materials and physical structures; or stops the teacher from working as expected and at the same time hampers students' learning. 
Centre for enhancement of learning and teaching 2003 cited in Agbatogun (2007), points out that large class syndrome has been attributed to the expansion in annual students' enrolment. At any rate, education as old as man has been characterized with mass instruction and this is the peculiarity of large classes in various institutions. Students, as many as three or four hundred, often cluster in a small hall tending to pay attention to the "talking and chalking" lecturer who occasionally scribbles on the chalkboard, while it is mostly assumed that, as the lecturer passes the necessary information through verbal means, learning takes place.

Large class phenomenon does not come about accidentally. Sometimes, financial constraints, lack of space and shortage of teachers give no option to the government and school proprietors other than running larges. The rapid increase in school enrolment and acute shortage of resource persons, learning materials and structures to match the growing population of students are factors responsible for abnormal class sizes in educational institutions. These factors left lecturers with no option other than to use lecture method which gives little or no room for learners to collaborate, explore or share idea. Zelkowitz (2008) opines that while your class may look more like a University lecture hall, your job is not to lecture. Just like teaching a small class, you must come up with engaging activities that keep all of your students interested and participating with the goal of improving their communication skills.

Large classes in many countries are alternative ways of utilizing the school staff in order to improve teaching and learning. Instruction can be designed in such a way that large classes can effectively be handled just like small classes. Projectors for instance can be used to deliver a lecture to a large class easily as small group. Both teachers and students benefits tremendously. With the advent of information technologies, a tutor can handle 400-500 students in class without stress in delivery and assessment. While public address system can be used to aid communication and learning activities, Computer based test (CBT) can be used to ease evaluation. This implies that a teacher who has the knowledge of using ICTs can still make his lesson in a large class interactive and collaborative. While there are numerous challenges when it comes to teaching large classes, there are many coping skills and activities that you can use to make your job easier.

\section{What is Team Teaching?}

Team teaching simply refers to teaching a class or group of students by more than one teacher. In other words, team teaching involves two or more teachers engaged in teaching group of learners using the same plan and materials. It could be at the same time where the teachers share responsibilities or at separate time. This means that team teaching provides opportunity for teachers to collaborate and harness their expert knowledge to enhance learning and teaching. Centre for the Enhancement of Learning and Teaching, City University of Hong Kong (1998) points out that in team teaching, a group of teachers, working together, plan, conduct, and evaluate the learning activities for the same group of students. Similarly, Goetz and Egallery (2000) define team teaching as involving a group of two or more teachers working together to plan, conduct and evaluate the learning activities for the same group of learners. Also, Quinn and Kanter (1984), define team teaching as "simply team work between two qualified instructors who, together, make presentations to an audience. Quinn and Kanter (1984) categorize team teaching into two. Category 'A' involves two or more instructors teaching the same students at the same time within the same classroom. Category ' $\mathrm{B}$ ' on the other hand involves instructors working together but do not necessarily teach at the same group of students nor necessarily teach at the same time.

In practice, team teaching has many models, but in general it is a means of organising staff into groups to enhance teaching. Teams generally comprise staff members who may represent different areas of subject expertise and who share the same group of students and a common planning period to prepare for the teaching. To facilitate this process, a common teaching space is desirable. However, to be effective, team teachers require much more than just a common meeting time and space. Teachers must collaborate, share ideas and cooperate to achieve common objectives. Team teaching of large classes is as innovation has eased the teachers' work by sharing responsibilities and harnessing ideas

\section{Team Teaching Models}

There are several team teaching models which team teachers may decide the suitable one to use in order to achieve their objectives. The choice of which model to use depends on the agreement of the instructors working as a team. The following are some:

\subsection{Traditional Team Teaching}

It is a model in which two teachers within a classroom take equal responsibility for teaching the students and are actively involved at all times. According to Zelkowitz (2008), both teachers plan and deliver instruction together, with each teacher equally responsible for the materials in the lesson .One may be teaching while the other is writing 
notes on the board, or one teacher presents the new material to the students, while the other prepares activities. This entails that both teachers are responsible for all the students. The model requires great deal of planning and cooperation between the team teachers.

\subsection{Lead and Support}

This involves two lecturers playing different roles simultaneously. One teacher plays the role of a lead teacher, while the other plays the role of a support teacher. The leading teacher teaches the class, while the supporting teacher provides assistance by going round the class elaborating important points; re-explaining parts of the lesson or providing follow up activities. Goetz and EGallery (2000) refer to this model as supportive instruction.

\subsection{Parallel Instruction}

This is a form of team teaching in which students are split into two groups and each teacher is responsible for teaching his group. The students are taught the same content with the same material simultaneously.(Alyssa 2008\&Judie 2007) This model allows teachers with distinctively different teaching style to work together.

\subsection{Differentiated Split Class}

This model involves splitting students of a large class into smaller groups according to teaching needs or achievements. Each educator provides the respective group with the instruction required to meet their learning needs. This model requires team teachers to do need analysis of the students. It is the needs that will determine the number of groups.

\subsection{The Monitoring Teacher}

Two teachers are involved in this model.One teaches the content to the students, while the other goes round the class and monitors students' behaviour and progress. The above models suggest that team teaching requires available teachers and space.

\section{Utilizing the Models}

This subsection presents the utilization of the team teaching models in large classes of English for Academic Purposes. Attempt is made to explain how each of the models can be utilized to teach one or more of the aspects of English language.

\subsection{Traditional Team Teaching}

Traditional team teaching model can be used for teaching almost all the aspects of English language. This study explains how it can be used for teaching writing tasks in a large class. There are many writing genres that undergraduate students engage in as part of the fulfillments for the award of certificates and degrees in tertiary institutions. Unlike speaking which is acquired naturally and unconsciously, writing is an art that has to be taught or learnt. It is a communication process which has diverse purposes such as to inform, educate or entertain. The students need to learn the skills appropriate for each writing genre or task as they are essential for studies and while on job after studies. Some of the writing genres include informal emails, memos, informal and formal letters, basic compositions (narrative, descriptive, expository, and argumentative) and research writing skills. Research or Report writing for instance is a tedious writing task that students engage in either as part of a course such as laboratory reports, field trip, and students' industrial work experience scheme (SIWES) or final year project report. Slides of the basic features of these reports as well as the appropriate language could be prepared by team teachers. While one of them will be showing the slides in the classroom, the other will be doing explanations to be finally followed by activities.

Writing tasks such as composition, letter writing, e-mail, memorandum, among others are usually taught to improve students' proficiency and communication competence. Traditional team teaching can be used to teach any of the above writing tasks. One teacher for instance may be showing slides of the features of composition writing such as finding the topic, brainstorming, outlining, introduction, body and conclusion. The other teacher could be saddled with the responsibility of explaining each slide.

\subsection{Lead and Support}

This model involves two teachers teaching simultaneously but performing different roles. The lead teacher for instance will be explaining grammatical structures such as sentences, clauses and phrases, while the support teacher will be writing the major points on the board, going round explaining important points or preparing activities. Activity for instance could be prepared on identification of sentences by structure (simple, compound or complex) or identifying dependent or independent clauses. The teachers could be made up of an experienced teacher serving as 
the lead teacher with assistant teacher serving as the supporting teacher. Also it could be made up of teachers of the same experience who may decide to exchange roles from time to time.Lead and support model can be used in teaching almost all aspects of English.

\subsection{Differentiated Split Class Model}

As explained earlier, this model requires dividing a large class into groups based on their learning needs .A large EAP class therefore can be divided based on programme of studies in order to teach the students the English language that they need to communicate effectively with their colleagues, their teachers and with the print. Available team teachers could also be divided based on their programme of interest, or aspect of English interested in or specialized in. An EAP practitioner needs the knowledge of the programme of study in order to have the ability to identify the language features and teach them accordingly. This implies that the language needed by students of a particular programme is a reflection of the course content which should not be separated from it. The following are suggested steps:

1 Identify the basic language needs of the students of a given programme of study.

2 Identify the language features of the writing task.

3 Design materials for teaching.

4 Plan to teach.

5 Decide on appropriate activity and method of evaluation

Though the needs of the students may be similar, the language they need and the features may differ. The language needed by Physics and Biology students for laboratory reports for example may differ, though the formats may be relatively similar. The teacher should put emphasis on the vocabulary (technical, jargon or argot ) as well as the dominant clause structures.

\subsection{Parallel Instruction}

This model is suitable for teaching EAP where a specific programme of study class is large and needs to be split. Team teachers are to use the same materials to teach the split classes. Slides, for example, could be prepared for teaching the features of letter of application for job and be used by the team teachers. This however may not be very effective as the rest of the models where two team teachers share the responsibility of planning and teaching.

\subsection{Monitoring Model}

This is good for teaching all the aspects of English. However, it is more effective for teaching literature. It is common to have a noisy or ruddy class during video show of a novel or a play that has been taught. While one teacher may be busy explaining selected characters or any aspect of the text, the monitoring teacher will be going round to make sure that every student pays attention since images can easily destruct attention. Equally, a poetry class demands a monitoring teacher since the class may be noisy during recitation of a poem.

\section{Conclusion}

Team teaching as revealed by this study is an effective means of achieving success in large classes. It brings together different teachers' ideas and teaching skills for the success of a group of learners. The study has highlighted how team teachers can utilized the different team teaching models for the teaching of English for Academic purposes. The split class model as pointed out is suitable for the teaching of English for Academic purposes in large classes. The splitting of the class can be done based on programme of studies since students of each programme have specific language needs. Team teachers could also be selected based on the interest of the teachers in a programme of study or area of interest in the course content. The paper has shed light on the importance of needs analysis in the teaching of English for Academic purposes which make teachers to focus on specific needs than the English for General purpose (EGP).

\section{References}

Ahsa, N, M. (2009). English for Academic Purposes (EOP), or English for Specific Purposes (ESP) English for Occupational Purposes (EOP). Who needs What?

Alyssa, Z. (2008). Sis Models for Collaborative Team Teaching: Scholastic (28/5/13).

Bradley, C., \& Green, E. (2011). Teaching Effectively in Large Classes. University of Regina Centre for Teaching \& Learning.

Centre for the Enhancement of Learning and Teaching, City University of Hong Kong (1998). 
Dudley-Evans, T., \& St.John, M. (1998). Development in ESP: A Multi-disciplinary Approach. Cambridge: Cambridge UniversityPress.

Goetz, K., \& EGallery. (2000). Perspectives on Team Teaching. Retrieved from http://www.ucalgary.ca/ egallery $(25 / 5 / 13)$.

Hutchinson, T., \& Waters, A. (1987). English for Specific Purposes. Cambridge, Cambridge University Press. http://dx.doi.org/10.1017/CBO9780511733031

Iwali, T., Kondo, K., Limm, S. J. D., Ray, E. G., Shimizu, H., \& Brown J. D. (1999). Japanese Laguage Needs Analysis. Retrieved from http://www.nflrc Hawaii.edu./Networks/NW13/NW13.pdf

Johns, A. (1999). English for Specific Purposes. Its History and Contribution. In Celce Murcia. M (ed.), Teaching English as a second or Foreign Language (pp. 67-77).

Judie, H. (2007). Collaborative Teaching: Are Two Teachers Better Than One? Retrieved from EverythingESL.net $(9 / 6 / 13)$.

Mohammadi V., \& Mouasvi N. (2013). Analyzing Needs Analysis in ESP: A (re) modeling. International Research Journal of Applied and Basic Sciences, 4(5), 1014-1020. Science Explorer Publications.

Songhori, M. H. (2008). Introduction to Needs Analysis. English for Specific Purposes, world issues 4, 2008, www.esp.world in for.

Tara B. (2008). Teaching Large Class. TEFL.net/Classroom Ideas/Teaching (28/5/13).

The Center for Teaching. (2012). Vanderbilt University, 1114 19th Avenue South, Nashville, 322-7290, Fax: (615) 343-8111, E-mail: cft@vanderbilt.edu 